\title{
Expansão canavieira \\ e o uso da terra \\ no estado de São Paulo
}

\author{
MARCIA REGINA GABARDO DA CAMARA I \\ ¿ CARLOS EDUARDO CALDARELLI II
}

\section{Introdução}

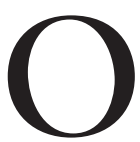

OBJETIVO deste artigo é avaliar os impactos da expansão da atividade ca-

navieira paulista sobre o uso da terra e seus desdobramentos em relação às demais atividades agropecuárias, delimitado o período de 1995 a 2013. Para isso, foi utilizado o modelo shift-share em duas etapas: incialmente, com vistas a decompor o valor da produção desse setor em efeitos área, rendimento e preço, e, na sequência, desagregar o efeito área nos subefeitos escala e substituição.

A experiência histórica do Brasil na produção de etanol, iniciada em 1975 com o ProÁlcool, colocou o país em posição de vanguarda ante a crescente demanda mundial de fontes renováveis e alternativas de energia, que se intensificou no fim dos anos 1990. A partir de então, o país tem passado por uma série de transformações nesse setor, que em 1999 foi desregulamentado e se reconfigurou totalmente (Moraes; Zilberman, 2014). Desde a cessão da intervenção governamental, e o advento dos veículos bicombustíveis em 2003, a demanda interna por etanol hidratado apresentou grande crescimento, passando de $4.603 .588 \mathrm{~m}^{3}$ vendidos pelas distribuidoras em 2000 para $10.816 .694 \mathrm{~m}^{3}$ em 2013, o que perfaz um crescimento de 235\% deste mercado (ANP, 2013).

Justifica-se este estudo em função da importância do setor na produção agrícola brasileira e paulista e a necessidade de compreensão de seus impactos. Hodiernamente, o Brasil é o maior produtor de cana-de-açúcar do mundo; a produção do setor sucroenergético no país, na safra 2013/2014, foi de 653.510 mil toneladas, sendo produzidos 37.710 mil toneladas de açúcar e 27.543 mil $\mathrm{m}^{3}$ de etanol (Unica, 2015).

No contexto do comércio exterior, esse também se mostra bastante dinâmico, e para o ano 2013, de acordo com o Mapa (2015), das exportações do agronegócio que foram de US\$ 99,97 bilhões, o setor sucroenergético representou $13,70 \%$ desse total - com US\$ 11,84 bilhões referentes à exportação de açúcar (11,8\% do total do agronegócio) e US\$ 1,86 bilhões à exportação de etanol ( $1,8 \%$ do total do agronegócio). 
Esse movimento tem provocado mudanças na paisagem agrícola das regiões afetadas, assim como impactos na realidade socioeconômica e ambiental dos municípios e regiões produtoras, o que suscita diversos questionamentos acerca desse processo. Diante de tais questionamentos os esforços em compreender as mudanças subjacentes à expansão do setor sucroenergético têm sido intensos. Diferentes estudos têm enfocado a temática, com distintos objetivos e abordagens metodológicas (Gilio, 2015).

O estado de São Paulo, em específico, tem chamado a atenção por sua forte representatividade nesse segmento. Das tradicionais regiões produtoras no nordeste brasileiro nos séculos XVI a XVIII, a produção migrou para o sul do Brasil e, desde os anos 1990, a região centro-sul lidera o ranking na produção e processamento desse setor, em especial São Paulo, maior estado produtor e processador. Na safra $2013 / 2014$ o estado representou $56,22 \%$ do total de cana-de-açúcar produzido no Brasil e, respectivamente, 63,57\% e 50,62\% dos totais produzidos de açúcar e etanol no país. Concernente ao processamento, para essa mesma safra, estavam em operação 182 usinas/destilarias de cana no estado (Unica, 2015).

Não obstante os dados apresentados revelarem a importância do setor sucroenergético para a economia paulista, assim como toda a literatura recente sobre o tema, essa expansão também suscita um intenso debate sobre o conflito pelo uso da terra decorrente e seus efeitos. Essa preocupação enfatiza principalmente os efeitos sobre o preço dos alimentos e a segurança alimentar. Destacam-se, nesse sentido, o estudo clássico de Galeano (2000), os apontamentos de Hoffmann (2006), Mitchell (2008), Rajagopal et al. (2009) e, recentemente, Lourenzani e Caldas (2014).

Conquanto estudos se debrucem sobre a questão food versus fuel, especificamente uso da terra, a efetiva mensuração é ainda escassa para o Brasil, sendo as investigações bastante conjecturais. A ideia de que o país apresenta uma grande extensão territorial parece subestimar essa questão. Dado o exposto, a proposta deste trabalho é mensurar a existência desse conflito para a atividade canavieira em São Paulo.

\section{Revisão de literatura}

A partir da década de 1950 a região centro-sul, especialmente São Paulo, assume um papel de destaque na produção canavieira do Brasil. Desde então, São Paulo é o maior produtor nacional de cana-de-açúcar e concentra grande parte da capacidade de processamento do país - produção de açúcar e etanol, e, contemporaneamente, a agroindústria canavieira é um dos principais setores de atividade da economia paulista (Shikida; Azevedo; Vian, 2011).

De acordo com Moraes e Zilberman (2014), dois momentos históricos são relevantes no processo de consolidação desse setor para o Brasil. Primeiramente, a forte intervenção estatal nos processos de planejamento e gestão nesse mercado - ProÁlcool de 1975 -, sendo a rígida atuação estatal e seu financia- 
mento fatores decisivos para a vigorosa expansão e, sobretudo, consolidação do mercado de biocombustíveis brasileiro. Um segundo momento significativo foi a desregulamentação ocorrida em 1999, quando o setor passa a operar sem subsídios estatais, sendo o mercado e seus determinantes bastante relevantes.

Desde então, fatores do mercado interno e, particularmente, externo passaram e influenciar os rumos do setor sucroenergético brasileiro. Abdala e Ribeiro (2011) verificam que a expansão canavieira a partir da década de 2000 foi estimulada principalmente pela expectativa de aumento de demanda interna por etanol, verificada com o crescimento da frota de veículos flex, da demanda externa, em função do Protocolo de Kyoto e a crescente demanda mundial de fontes renováveis e alternativas de energia, sendo relevante também a elevação dos preços internacionais do açúcar.

Indubitavelmente essa expansão vem suscitando diversos questionamentos acerca do setor, desde os impactos socioeconômicos sobre as regiões produtoras - contribuição para produto e renda e toda uma gama de questões sociais -, aos questionamentos ambientais, segurança alimentar, problemas hídricos e questões fundiárias (Gilio, 2015). A literatura nacional e internacional a esse respeito tem ampliado de maneira considerável.

Contudo, por se tratar de um fenômeno recente - expansão acelerada em meados dos anos 2000 -, alguns desses questionamentos ainda permanecem em aberto. Estudos tais como Bacchi e Caldarelli (2015), Satolo e Bacchi (2013) e Moraes (2007) evidenciam a possibilidade de crescimento econômico advindo do setor, com geração de emprego e renda, salientando que o segmento pode gerar benefícios líquidos positivos, incluindo sociais, à região produtora.

Por outro lado, com a emergência de diversos trabalhos que ressaltam as potenciais consequências negativas da produção de biocombustíveis, tais benefícios obtidos pela produção e consumo de combustíveis de origem agrícola vêm sendo confrontados na literatura científica, notadamente no que se refere a um possível ônus social destinado às regiões produtoras, como a precarização das relações e condições de trabalho, alocação e uso da terra, pressão sobre preço dos alimentos, questão hídrica, questões fundiárias entre outros aspectos (Gilio, 2015; Lourenzani; Caldas, 2014; Rajagopal et al., 2009; Mitchell, 2008). Para o escopo deste artigo o impacto sobre o uso da terra é enfatizado.

Em clássico estudo sobre o subdesenvolvimento da América Latina, Galeano $(2000, \text { p.6 })^{1}$ é peremptório acerca da substituição da terra destinada a alimentos em produção de biocombustíveis e bens de exportação: “Agora é a vez [...] do novo cardápio dos automóveis, que já não comem apenas petróleo ou gás, mas também milho e cana-de-açúcar de imensas plantações. Dar de comer aos carros é mais importante que dar de comer às pessoas”. O autor afirma que os processos de conversão da produção de alimentos em culturas para exportação são temerários para o desenvolvimento rural na América Latina e para a questão fundiária - concentração de terras. $\mathrm{O}$ aludido autor afirma que a 
pobreza rural na América latina guarda profunda relação com os "monopólios" da terra - monocultura e concentração de terras.

Estudos internacionais também se mostram alarmados com o fenômeno em análise. Mitchell (2008) destaca que o conflito decorrente do uso da terra na produção de biocombustíveis no mundo, sobremaneira em países subdesenvolvidos e em desenvolvimento, contribuiu em aproximadamente $75 \%$ na chamada crise de alimentos de 2007/2008, qual seja, elevação do índice agregado de preço de commodities alimentares. Nessa mesma linha, Rajagopal et al. (2009), além de associar a elevação no preço dos alimentos de 2007/2008 ao conflito food versus fuel, destacam ainda que a competição pelo uso do solo tem efeitos sobre a questão agrária dos países envolvidos, alterando o mercado de terras, trabalho e insumos. Os referidos autores destacam a importância de medidas quantitativas acerca do uso da terra.

Sobre o conflito pelo uso da terra decorrente da expansão canavieira em São Paulo - início dos anos 2000 -, Hoffmann (2006) sinalizou, no início desse processo, a preocupação com essa questão. $\mathrm{O}$ autor pondera que pode ocorrer a substituição de áreas destinadas à produção de alimentos por lavouras canavieiras, mas que se acredita que a grande expansão ocuparia, sobretudo, pastagens. Esse apontamento é, em parte, refutado por Lourenzani e Caldas (2014) em estudo para a região oeste paulista. Os aludidos autores demonstram que para aquela região do estado a expansão canavieira não está circunscrita apenas às pastagens, eles asseveram que tem ocorrido um movimento de expulsão de culturas alimentares e pecuária, chama atenção a conclusão dos autores sobre os reflexos negativos para com a agricultura familiar naquela região - redução da produção de alimentos.

Bacchi e Caldarelli (2015) e Satolo e Bacchi (2013) ponderam que a produção canavieira em São Paulo apresenta algumas vantagens, em especial geração de emprego e renda, contudo algumas consequências do rápido crescimento dessa produção não são levadas em consideração nesses estudos e não podem ser negligenciadas, com destaque para os efeitos sobre a oferta e os preços de alimentos; principalmente devido à competição no uso da terra. Hoffmann (2006) assevera que não se pode falar em insegurança alimentar, pois no Brasil ela está intimamente associada à pobreza; argumenta ainda que a pobreza poderá ser reduzida com a ampliação do emprego e da renda derivados da produção da agroindústria canavieira. Essa assertiva do autor deve ser contrastada com os dados do IEA/SP (2015), que dão conta da crescente mecanização observada em São Paulo, e a safra 2013/2014 apresenta índice de mecanização da ordem de $84,8 \%$, o que parece limitar o argumento de Hoffmann (2006), porquanto poderá colaborar para ao desemprego.

Adicionalmente, segundo Adami et al. (2013), em levantamento de imagens de satélite, o plantio de cana de açúcar em terras paulistas no período 2005 a 2011 cresceu e avançou em áreas de pastagens $(63,1 \%)$, culturas anuais ou 
temporárias $(32,1 \%)$, citros $(3,7 \%)$, terras com vegetação arbórea e matas ciliares $(0,2 \%)$ e áreas de reflorestamento $(0,1 \%)$, fato que parece reforçar a questão de que a cana tem se expandido de forma acentuada pela expansão de área, inclusive sobre as antes destinadas à produção de alimentos.

Demattê (2014) e Nyko et al. (2013) também identificam tal processo, ao verificar que a atividade canavieira no Brasil, sobretudo em sua região mais intensiva, baseia-se na expansão da área desta atividade. Segundo os referidos autores, fatores conjunturais, tais como clima, falta de renovação adequada dos canaviais, envelhecimento dos canaviais e redução dos investimentos na lavoura, e fatores estruturais, como questões institucionais, ações equivocadas do governo e necessidade de pesquisa e tecnologia, têm sido responsáveis pela tendência de queda nos ganhos de produtividade desta atividade no Brasil.

Nyko et al. (2013) aprofundam a discussão dos fatores estruturais; os autores verificam uma queda no ritmo dos ganhos de rendimento agrícola e o declínio de indicadores de difusão tecnológica, o que tem gerado efeitos negativos sobre os resultados das tecnologias agrícolas e desempenho do setor a partir de 2008. O estudo observa queda na produtividade média, redução nas taxas de crescimento na produtividade, queda no Índice de Atualização Varietal (IAV) - medida de difusão tecnológica que mensura o ritmo com que as novas variedades lançadas são plantadas nos canaviais brasileiros - e o aumento no Índice de Concentração Varietal (ICV). Constata-se ainda a presença e ampliação do domínio de variedades antigas nas lavouras canavieiras e menor ritmo de substituição de variedades antigas por novas variedades a partir dos anos 2000, período no qual o setor sucroenergético acelerou seu ritmo de expansão. Portanto, o setor é caracterizado, na década de 2000 , por menores retornos e possibilidades de investimentos públicos e privados no desenvolvimento de novas variedades, base genética limitada, limitações de melhoramentos utilizando técnicas clássicas e de melhoramento genético, transgenia, entre outros, assim como por limitações na pesquisa e na disseminação das inovações.

Nyko et al. (2013) concluem que no começo da década de 2000 os canaviais paulistas apresentavam baixa concentração e elevada diversificação de variedades, e que a partir de 2010 tais condições se deterioram, de forma que os canaviais existentes estão mais suscetíveis a novas doenças e a fortes variações climáticas. O baixo desempenho do setor após 2008 conta também com fatores conjunturais - crise econômica, fatores climáticos e os demais já citados - e fatores estruturais - questão varietal, efeitos da mecanização da colheita ao plantio e do protocolo ambiental - o que sinaliza uma tendência à estagnação da produtividade agrícola. Nesse sentido, pode-se inferir que a expansão em área é uma estratégia menos custosa com maiores retornos no curto prazo e que não apresenta tendência de reversão para um futuro próximo.

Dado o exposto, é visível a importância do tema em debate, com destaque ao fato de que algumas análises têm sido limitadas a regiões específicas ou a pe- 
ríodos mais curtos de tempo, outras, por sua vez, atenuam a questão do conflito pelo uso da terra sob a afirmativa de que não existe insegurança alimentar no Brasil, negligenciando que o referido conflito afeta além do preço dos alimentos, questões como posse da terra, pobreza rural e agricultura familiar, como asseveram Rajagopal et al. (2009) e Mitchell (2008).

Ademais, deve-se observar que esse conflito pelo uso da terra compõe, como destaca Nyko et al. (2013), uma estratégia menos custosa de expansão da produção baseada no uso extensivo da terra, adotada para contrapor as revezes do mercado e a tendência de estagnação e queda da produtividade, caracterizando-se, portanto, um problema estrutural.

\section{Metodologia}

\section{Modelo shift-share}

O modelo shift-share, ou ainda análise diferencial-estrutural, tem sido utilizado em vários campos do conhecimento econômico devido à sua flexibilidade de aplicação e interpretação. Basicamente, esse método é usado com a finalidade de decompor taxas em fontes de crescimento.

A análise shift-share utilizada neste trabalho divide-se em duas etapas, como proposto em Caldarelli (2010). Primeiramente, é calculada a decomposição da variação do valor da produção canavieira nos efeitos área, rendimento e preço. Procedimento semelhante foi adotado por Araújo e Campos (1998), na análise da evolução do valor da produção do cacau, Caldarelli (2010) para grãos no Brasil e por Abdala e Ribeiro (2011) para a cana no estado de Goiás.

Nessa primeira etapa de aplicação do método, segundo Araújo e Campos (1998), mede-se a variação no valor da produção entre dois pontos - sendo o início o período 0 e o fim o período $t$. Logo, o valor da produção será:

No período inicial

(Eq. 1)

$$
V_{0}=A_{0} R_{0} P_{0}
$$

\section{No período final}

$$
V_{t}=A_{t} R_{t} P_{t}
$$

em que:

$V$ é o valor da produção do bem;

$A$ é área com o bem - em hectare;

$R$ é o rendimento da cultura - em $\mathrm{kg} /$ hectare, e;

$P$ é o preço pago ao produtor $-\mathrm{em} \mathrm{R} \$ / \mathrm{kg}$.

Considerando apenas uma alteração na área no período $t$, o valor da produção será:

(Eq. 3)

$$
V_{t}^{A}=A_{t} R_{0} P_{0}
$$


Se a variação no período $t$ ocorresse na área e rendimento, mantendo-se constante o preço, o valor da produção seria:

(Eq. 4)

$$
V_{t}^{A R}=A_{t} R_{t} P_{0}
$$

Por sua vez, a variação total no valor da produção entre os períodos 0 e $t$ seria: (Eq. 5)

$$
V_{t}-V_{0}=\left(A_{t} R_{t} P_{t}\right)-\left(A_{0} R_{0} P_{0}\right)
$$

$$
V_{t}-V_{0}=\left(V_{0}^{A}-V_{0}\right)+\left(V_{t}^{A R}-V_{t}^{A}\right)+\left(V_{t}-V_{t}^{A R}\right)
$$

(Eq. 6)

\section{sendo:}

$V_{t}-V_{0}$ a variação total no valor da produção;

$V_{0}^{A}-V_{0}$ o efeito área;

$V_{t}^{A R}-V_{t}^{A}$ o efeito rendimento, e;

$V_{t}-V_{t}^{A R}$ o efeito preço.

De acordo com Adbdala e Ribeiro (2011), os efeitos explicativos (Eq. 6) podem ser apresentados na forma de taxas anuais de crescimento, que somadas resultam na taxa anual de variação do valor da produção.

O efeito área constitui um indicador de mudanças na produção advindo de alterações na estrutura agrária, em que se supõem os demais efeitos constantes. A expansão deste efeito sinaliza o aumento da produção pela incorporação de novas áreas - uso extensivo do solo.

O efeito rendimento captura o aumento da produção decorrente de aumento da produtividade, ou seja, diferenciais tecnológicos nos fatores de produção (Abdala; Ribeiro, 2011). O efeito preço, por sua vez, mensura a evolução dos valores de produção decorrentes de evolução dos preços reais do bem, considerados os demais fatores constantes (Caldarelli, 2010).

Em uma segunda etapa, tal como descrito por Caldarelli (2010), a partir de uma modificação da análise shift-share o efeito área, uma das fontes de crescimento do valor da produção, é decomposto em dois sub efeitos: o efeito escala e o efeito substituição. O modelo analítico que descreve essa abordagem, como proposto por Yokoyama e Igreja (1992), é representado pela seguinte expressão: (Eq. 7)

$$
A_{i t}-A_{i 0}=\left(\alpha A_{i 0}-A_{i 0}\right)+\left(A_{t}-\alpha A_{i 0}\right)
$$

em que:

$A_{i t}-A_{i 0}$ é a variação da área cultivada com a atividade $i$ entre o período 0 e $t$,

$$
\text { a } A_{i 0}-A_{i 0} \text { representa o efeito escala, e; }
$$




$$
A_{i t}-\alpha A_{i 0} \text { é o efeito-substituição. }
$$

sendo:

(Eq. 8)

$$
\alpha=\frac{A_{S t}}{A_{S 0}}
$$

$$
A_{S 0}=\sum_{i} A_{i 0}
$$

(Eq. 10)

$$
A_{S t}=\sum_{i} A_{i 1}
$$

em que $A_{i}$ corresponde à área cultivada com a i-ésima atividade; $A_{S 0}$ é o tamanho do sistema no período $0 ; A_{\S}$ é o tamanho do sistema no período $t$; e a é a relação entre $A_{S t}$ e $A_{S 0}$, que mede a alteração no tamanho do sistema de produção.

O efeito escala é dado pela variação na área cultivada resultante apenas da alteração do tamanho do sistema - produção total -, mantendo inalterada sua participação dentro desse. Se o valor for positivo para esse efeito, isso representa uma tendência de expansão da cultura; se for negativo, representa uma tendência de diminuição na produção da cultura dentro do sistema. Os valores obtidos no efeito escala, para cada produto, mostram o comportamento de cada cultura, se a ampliação ou a contração da área total fosse distribuída de modo uniforme entre elas.

Por sua vez, o efeito-substituição mostra a variação da participação de cada cultura dentro do sistema, ou seja, refere-se à diferença entre a variação real da área cultivada entre os períodos em análise e o efeito escala. Isso quer dizer que quando o efeito substituição for negativo, por exemplo, não significa, necessariamente, que sua área cultivada tenha sido reduzida; ela pode, simplesmente, ter se expandido, porém, numa magnitude menos que proporcional ao crescimento total da área na região em análise. Isso implica dizer que essa cultura teve suas áreas, de modo geral, substituídas por outra cultura que se expandiu mais que proporcionalmente ao crescimento da área total dentro do sistema.

Caso o efeito substituição apresente sinal positivo, a situação é simétrica à supracitada. Em suma, as culturas que apresentarem efeito substituição positivo substituíram outras culturas e as atividades que apresentarem efeito substituição negativo foram substituídas por outras (Araújo; Campos, 1998).

\section{Fontes e tratamentos de dados}

Para área plantada de cana, lavouras temporárias e lavouras permanentes foram utilizados os dados da Pesquisa Agrícola Municipal do Instituto Brasileiro de Geografia e Estatística - PAM/IBGE. Os dados relativos a áreas de pastagem - capim para semente, pastagem natural e pastagem cultivada - foram obtidos junto ao Instituto de Economia Agrícola de São Paulo (IEA/SP). Para os preços 
pagos aos produtores foram utilizadas as séries divulgadas pela União dos produtores de bioenergia (Udop).

A série de rendimento médio foi construída com base nos dados de área plantada (em hectare) da PAM/IBGE e dados de produção do sistema Canasat/Inpe.

Os preços foram transformados em valores reais utilizando o IGP-DI - divulgado pela Fundação Getulio Vargas e coletados no Ipeadata, tomando como base dezembro de 2013.

A análise, feita com dados anuais, abrange o período de 1995 a 2013. Justifica-se esse período pela irregularidade de séries de preços anteriores a 1995, ademais as variações de preço se tornam mais relevantes no período pós-desregulamentação do setor.

\section{Resultados e discussão}

O Brasil é o maior produtor de cana-de-açúcar do mundo, seguido por Índia, Tailândia e Austrália. Os dados do IBGE (2015) mostram que a área plantada no país, em 2013, ${ }^{2}$ foi de 10.223 milhões de hectares, e que São Paulo é o estado com a maior participação na produção nacional, com $56,51 \%$ do total - 5.415 milhões de hectares de área plantada e produção de 434 milhões de toneladas. Nas últimas safras aproximadamente $51 \%$ da produção de cana no país tem se destinado à produção de etanol (anidro e hidratado) e $49 \%$ à produção de açúcar (Unica, 2015).

De acordo com Abdala e Ribeiro (2011), tais resultados são reflexos da forte expansão do setor canavieiro nas últimas décadas no Brasil, estimulado pela expectativa de aumento de demanda interna por etanol, dado o aumento na frota de carros bicombustíveis, a demanda externa por energia limpa, especialmente decorrente das diretrizes do Protocolo de Kyoto e elevações no preço internacional do açúcar.

Esse processo de expansão tem um importante impacto sobre o setor agropecuário brasileiro, com destaque para região centro-sul e São Paulo, porquanto foi o estado que apresentou o maior crescimento da produção no Brasil. Em 1995, o estado era responsável por 48,70\% da área plantada no país, passando, em 2000, para 50,91\% e 52,96\% no ano 2013 (Figura 1). A expansão da atividade canavieira em São Paulo entre 1995 e 2013 se deu em termos de distribuição espacial, onde é possível observar (Figura 1) uma desconcentração geográfica da produção para quase todas as regiões no período em questão, principalmente Norte e Oeste. Das tradicionais regiões produtoras de Ribeirão Preto, Araraquara, Piracicaba, Jaú e vale do Paranapanema, as lavouras canavieiras expandiram-se para todo o estado e destacaram-se em termos de importância econômica. 

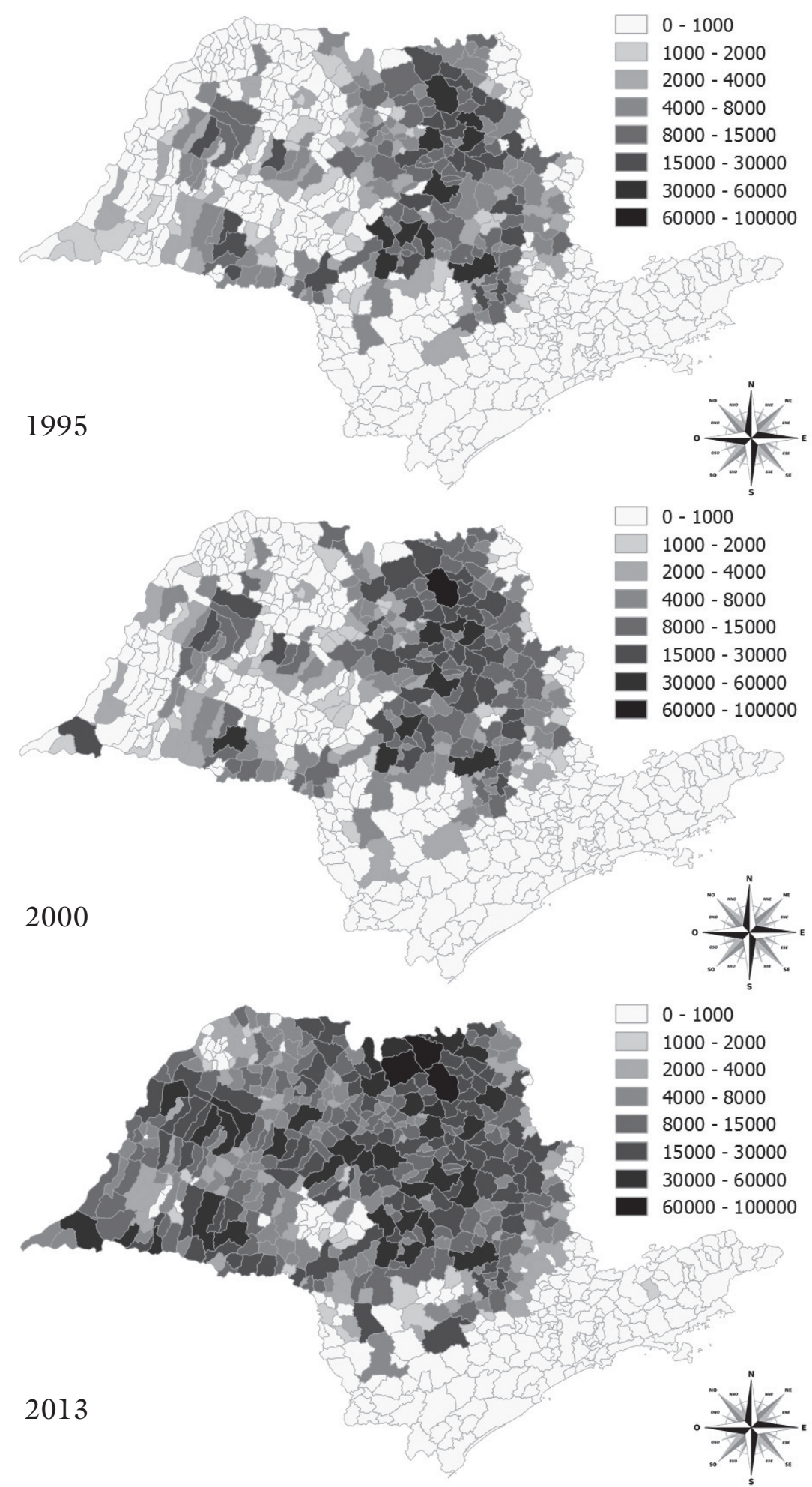

Figura 1 - Evolução da área de plantada de cana-de-açúcar em São Paulo, para 1995, 2000 e 2013 - em hectares por município.

Fonte: PAM/IBGE (2015). 
Os dados da Tabela 1 mostram a evolução dos indicadores de produção do setor para o estado de São Paulo. Pode-se observar (Tabela 1), no período em questão, a grande expansão da atividade canavieira em São Paulo. Entre 2000 e 2013 a área plantada no estado expandiu $119,75 \%$ - cerca de 2,97 milhões de hectares - e a produção $129,61 \%$ - expansão de 245,03 milhões de t. Esse avanço também pode ser observado na participação da lavoura canavieira em relação à área total plantada no estado. Em 2000, aproximadamente 43,27\% da área plantada no estado era cana, sendo que, no ano de 2013 , este percentual passou a ser de $66,61 \%$.

Tabela 1 - Indicadores da produção canavieira no estado de São Paulo de 2000 a 2013

\begin{tabular}{c|c|c|c}
\hline Ano & $\begin{array}{c}\text { Área plantada } \\
\text { (em milhões de } \\
\text { hectares) }\end{array}$ & $\begin{array}{c}\text { Produção } \\
\text { (em milhões de t) }\end{array}$ & $\begin{array}{c}\text { Participação da } \\
\text { cana em relação à } \\
\text { area total plantada } \\
\text { no estado (em \%) }\end{array}$ \\
\hline 2000 & 2,48 & 189,04 & 43,27 \\
\hline 2001 & 2,57 & 198,93 & 43,99 \\
\hline 2002 & 2,66 & 212,71 & 44,86 \\
\hline 2003 & 2,82 & 227,98 & 45,12 \\
\hline 2004 & 2,95 & 239,53 & 45,56 \\
\hline 2005 & 3,08 & 254,81 & 46,40 \\
\hline 2006 & 3,50 & 289,30 & 51,23 \\
\hline 2007 & 3,89 & 329,10 & 57,02 \\
\hline 2008 & 4,54 & 386,06 & 59,93 \\
\hline 2009 & 4,98 & 408,45 & 65,18 \\
\hline 2010 & 5,07 & 426,57 & 64,92 \\
\hline 2011 & 5,21 & 427,36 & 65,75 \\
\hline 2012 & 5,17 & 406,15 & 65,33 \\
\hline 2013 & 5,45 & 434,07 & 66,61 \\
\hline
\end{tabular}

Fonte: Elaborado pelo autor com dados de PAM/IBGE (2015) e Ipeadata (Ipea, 2015).

Nota: Considera-se como total a soma de lavoura temporária e permanente de São Paulo.

Com base na análise dos dados apresentados é possível inferir que os ganhos de produção canavieira em São Paulo, assim como apontado por Veiga Filho e Yoshii (1992) no início dos anos 1990, e recentemente por Lourenzani e Caldas (2014), são advindos da expansão territorial e substituição de culturas.

Esse fato pode ser constatado por meio da Figura 2, que apresenta a evolução da participação da lavoura canavieira na produção agrícola dos municípios paulistas - para 1995, 2000 e 2013. 


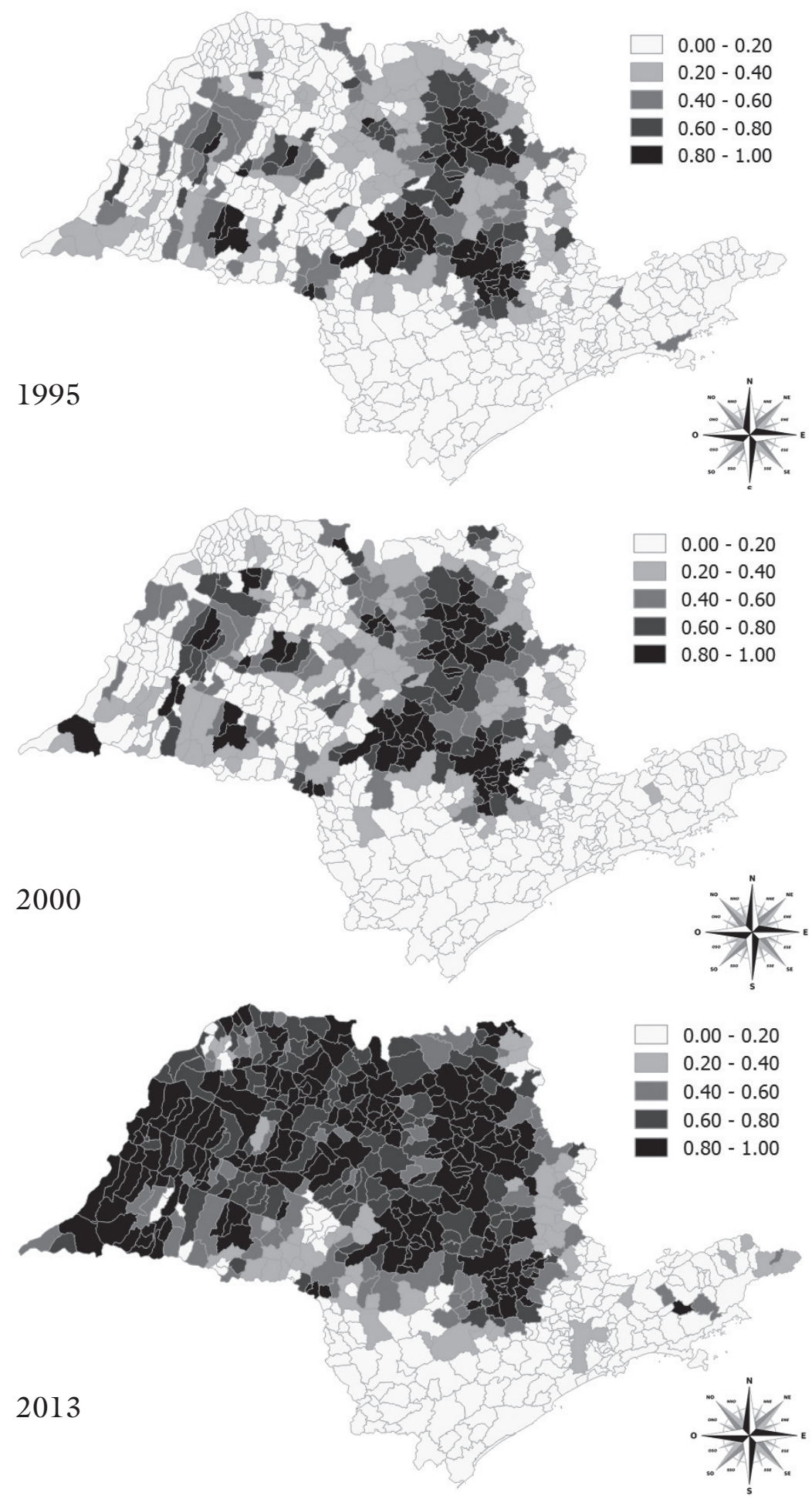

Figura 2 - Participação das lavouras de cana-de-açúcar na produção agrícola dos municípios paulistas, para 1995, 2000 e 2013 - em \% do total.

Fonte: PAM/IBGE (2015).

Nota: Considera-se como total a soma de lavoura temporária e permanente dos municípios. 
Das tradicionais regiões produtoras do início da década de 1990 - Ribeirão Preto, Araraquara, Piracicaba, Jaú e vale do Paranapanema -, hodiernamente, à exceção da região litorânea do estado, todas as demais apresentam elevada concentração de cana na produção agrícola dos munícipios. Em 2013, dos 645 munícipios do estado 332 apresentam participação de cana superior a $60 \%$ de suas áreas agrícolas - lavoura temporária e permanente - e 224 destes tem participação superior a $80 \%$ (Figura 2).

Conquanto o estado de São Paulo apresente taxas de crescimento da área plantada e de produção maiores que para o Brasil, no que concerne à produtividade a mesma tendência não é observada (Figura 3). A taxa geométrica de crescimento da produtividade ${ }^{3}$ da cana no Brasil é de $0,49 \%$ ao ano, enquanto para São Paulo essa taxa é de $0,18 \%$ ao ano. Na última década, o diferencial entre a produtividade do Brasil e de São Paulo vem diminuindo ao longo do tempo; e tanto Brasil quanto São Paulo apresentaram decréscimos em suas produtividades nas últimas três safras.

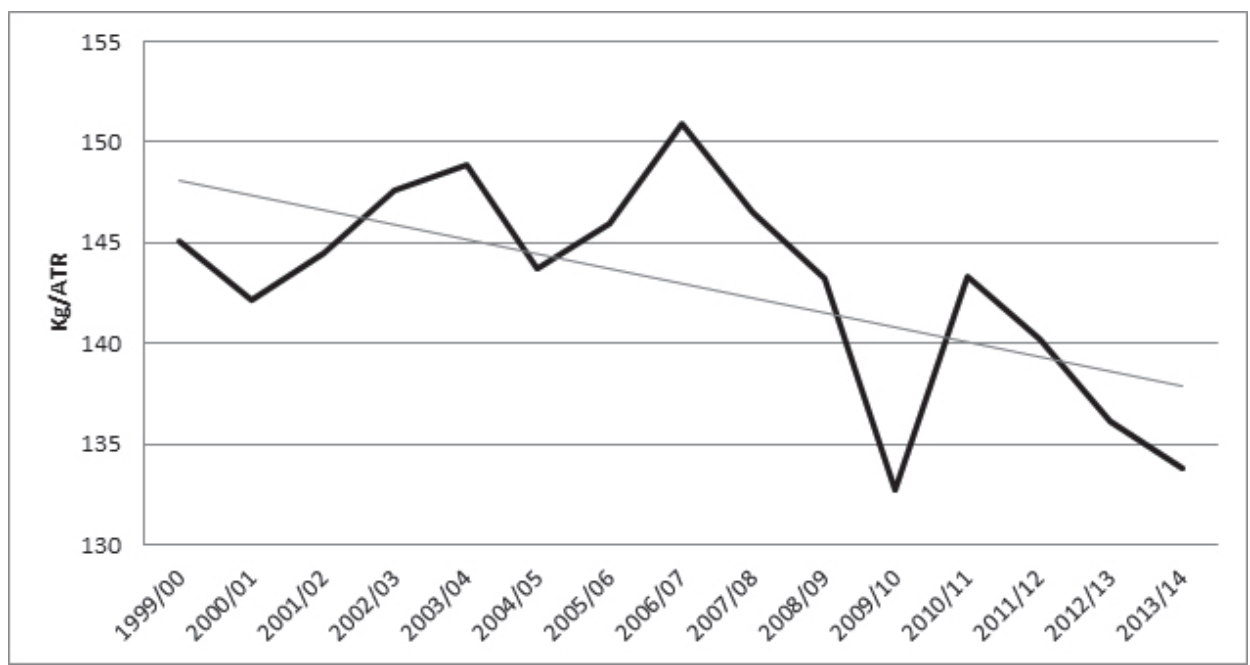

Figura 3 - Produtividade da cana de açúcar para Brasil e São Paulo de 1995 a 2013 em t/ha.

Fonte: Elaborado pelo autor com dados de PAM/IBGE (2015).

O Indicador de Açúcar Total Recuperável (ATR), também levado em consideração como medida de produtividade da cana paulista, porquanto está relacionado ao sistema de pagamento e valor desse produto, apresenta taxa de crescimento quase nula no período $1999 / 2000$ a 2013/2014; houve uma grande queda entre as safras 2006/2007 até 2009/2010 (Figura 4). Dessa feita, assim como destacam Durigan, Siqueira e Franco (2007) e Camargo et al. (2008), aventa-se a questão da produção canavieira no estado de São Paulo basear-se na expansão da margem extensiva, isto é no uso da terra. 


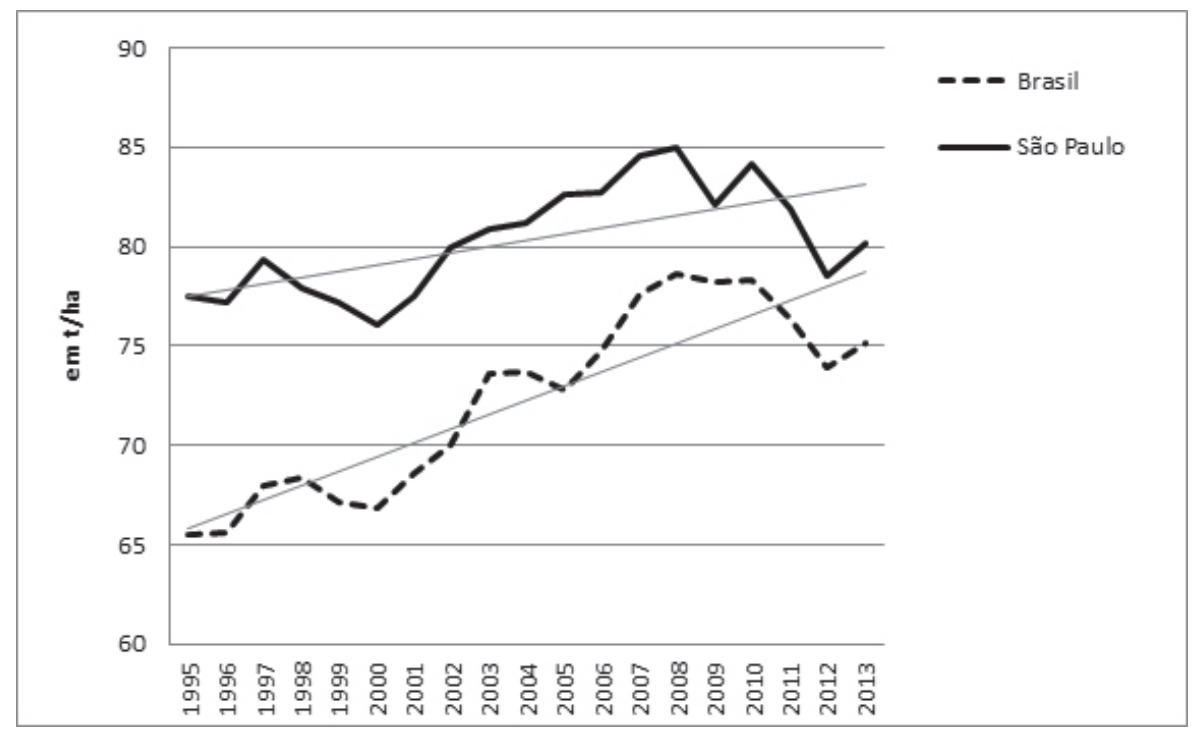

Figura 4 - Indicador de Açúcar Total Recuperável (ATR) para produção paulista ano-safra de 1999/00 a 2013/14 - em kg/ATR.

Fonte: Unica (2015).

Para a análise dos impactos da competição pelo uso do solo decorrente da expansão canavieira em São Paulo, a Figura 5 apresenta os dados acerca da evolução das áreas de lavouras e pastagens no estado. Pode-se observar que, no período em voga, a produção de cana no estado mostra um acelerado processo de expansão, principalmente pós-2003. Nesse mesmo período, também é possível observar uma forte redução nas áreas de pastagem cultivada e uma redução menos acentuada nas lavouras temporárias, permanentes e nas pastagens naturais. Em relação à pastagem cultivada, os dados da Pesquisa Pecuária Municipal do IBGE mostram que entre 2003 e 2013 o efetivo de rebanho bovino em São Paulo apresentou redução de 25,3\%; enquanto para o Brasil esse indicador, no período, apresentou aumento de 8,30\%.

Evidências do conflito pelo uso do solo decorrente da expansão do setor em questão fora levantando por Hoffmann (2006, p.2):

[...] Passemos a focalizar nossa atenção nas possíveis consequências do rápido crescimento da produção de etanol no Brasil. Este crescimento terá efeitos no preço de alimentos? É óbvio que sim, devido à competição no uso dos recursos.

O autor leva em consideração os possíveis reflexos do setor sucroenergético sobre a utilização dos recursos naturais, o estudo destaca os possíveis impactos socioeconômicos, a questão da segurança alimentar e o uso da terra. Como a expansão era bastante recente à época da referida pesquisa, tais efeitos não foram mensurados, apenas apontados como possíveis reflexos do avanço do setor. Deve-se, contudo, destacar que o aludido autor pondera tais efeitos pelos possíveis avanços de renda advindos da atividade. 
A Figura 5 corrobora a análise supramencionada de que a atividade canavieira tem reflexos no uso da terra e substituição de lavouras, é possível identificar que essa expansão está correlacionada com a redução tanto de pastagens (natural e cultivada) - efeito mais intenso -, quanto de lavouras temporárias e permanentes - substituição menos intensa.

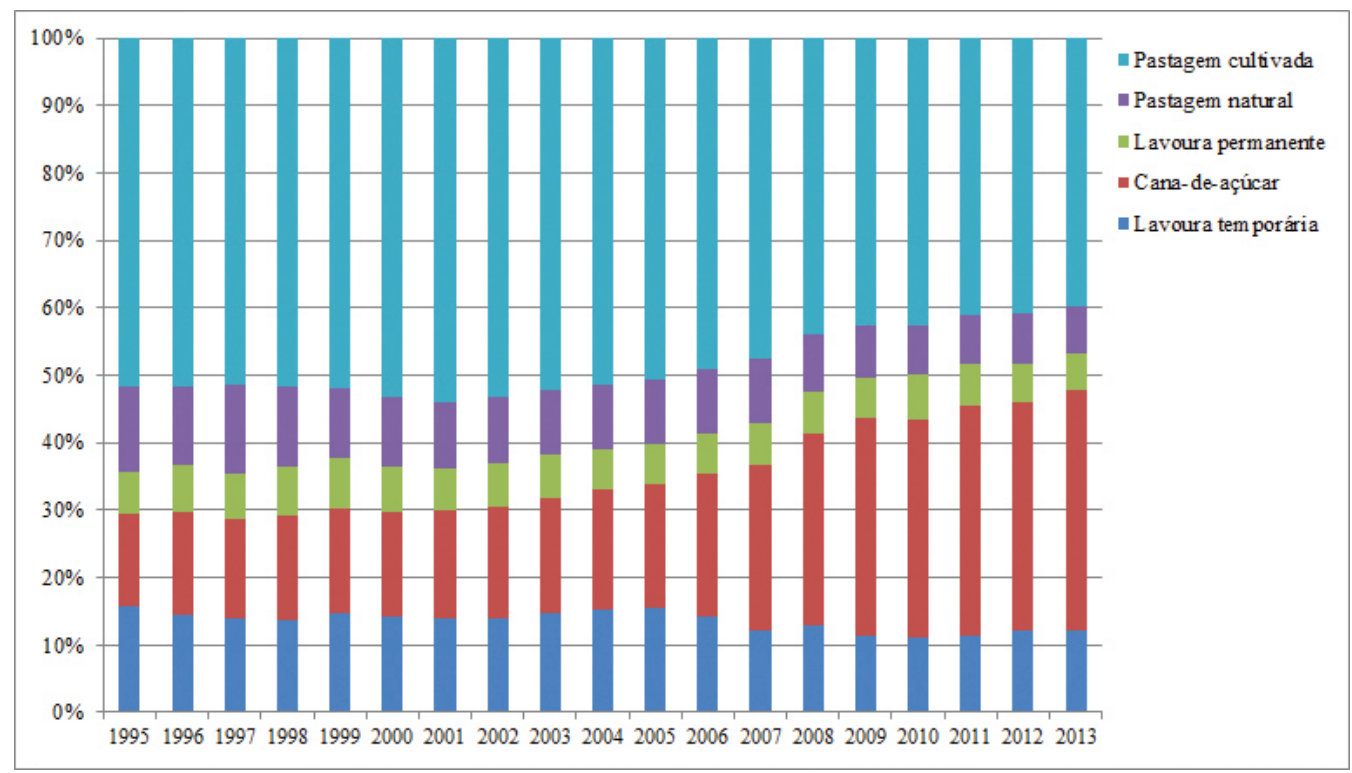

Figura 5 - Evolução da área de lavouras (temporárias e permanentes), cultivo de cana-de-açúcar e pastagem (natural e cultivada) em São Paulo, de 1995 a 2013 - em \% do total do sistema.

Fonte: Elaborado pelo autor com dados de PAM/IBGE (2015), Ipeadata (Ipea, 2015) e IEA/SP (2015).

* Considera-se como total do sistema, a soma de lavoura temporária, lavoura permanente e área de pastagem, que compreende capim para semente, pastagem natural e pastagem cultivada.

** A evolução dos percentuais referentes à lavoura temporária não incluem valores da cana-de-açúcar, que são analisados separadamente.

No que diz respeito às taxas e fontes de crescimento do valor real da produção canavieira (em R\$) - deflacionado pelo IGP-DI (FGV) - no estado de São Paulo (Tabela 2), observa-se que a variação total do valor da produção, para todo o período em análise, fora positiva, com destaque para 1995 e 2001, período no qual o valor da produção canavieira cresceu 60,86\% e entre 2008 a 2013 , com crescimento de $47,44 \%$ na produção, a despeito do setor enfrentar uma crise pós-2010.

No que concerne às fontes de crescimento (Tabela 2), verifica-se que no subperíodo 1995/2001, ainda sobre os impactos da desregulamentação do setor, o efeito preço e área foram os que mais contribuíram para o aumento do 
valor da produção, respectivamente 47,16\% e 13,64\%; neste, cumpre destacar o efeito quase nulo da produtividade - efeito rendimento $0,05 \%$. No segundo subperíodo $(2002 / 2007)$ predomina o efeito área como fator de expansão da produção canavieira $(46,20 \%)$, o efeito rendimento, por sua vez, apresenta contribuição de $8,51 \%$, entre outros fatores, como resultado dos esforços do setor em ganhar competitividade, assim como destacado por Shikida, Azevedo e Vian (2011).

Por fim, o último subperíodo (2008/2013) mostra uma acentuada contribuição dos preços como fonte de explicação do aumento no valor da produção (42,24\%); o efeito área também apresentou-se positivo, responsável por $13,67 \%$ do aumento no valor da produção canavieira.

O que chama atenção quanto aos resultados da Tabela 2 é a importância da expansão da área como fator explicativo da evolução no valor da produção canavieira em São Paulo. Os resultados apontam para o fato de que a evolução do setor no estado é baseada em ganhos na margem extensiva - expansão de área - e variações advindas do mercado - efeito preço -, em que os ganhos de produtividade foram quase nulos no período. Em linha com tal resultado, o estudo de Shikida, Azevedo e Vian (2011) mostra que os ganhos tecnológicos e, sobretudo fomento e difusão de P\&D em todos os níveis do setor sucroenergético, apresentam-se como grandes desafios para o setor.

Quando se discute o uso da terra, os resultados acima expostos são bastante preocupantes, pois a expansão do setor canavieiro baseada no uso extensivo do solo, além da condição de segurança alimentar, como destacado por Lourenzani e Caldas (2014), faz refletir os possíveis efeitos de uma crise no setor como a que se encontra em curso desde 2010 e é caracterizada por queda nos preços, e seus reflexos sobre a economia paulista com algumas regiões fortemente atreladas à atividade.

A Tabela 3 apresenta o resultado da segunda etapa da metodologia utilizada, a saber, a decomposição do efeito área em subefeitos escala e substituição - para cana-de-açúcar, lavouras permanentes e temporárias e área de pastagem. Os resultados obtidos mostram que, em todos os subperíodos - 1995/2001, 2002/2007 e 2008/2013 -, a única atividade que apresentou expansão de área (em hectares) no estado de São Paulo foi a cultura de cana-de-açúcar. As áreas com lavouras temporárias, permanentes e de pastagem apresentaram recuo nos três subperíodos observados. Uma importante constatação quando observada a redução das áreas de pastagens e lavouras temporárias é que essas culturas recuam explicadas em grande parte pelo efeito substituição, qual seja, cedendo área para outras culturas, e como no sistema em análise apenas a cana se expande, infere-se que esse segmento absorveu tais áreas.

Esse resultado contraria o que fora apontado por Hoffmann (2006), que projetara que a expansão do setor canavieiro no estado de São Paulo se daria predominantemente em decorrência do uso de terras destinadas a pastagens, 
assim como também diverge de Camargo et al. (2008) e Adami et al. (2013), que minoraram o efeito de tal expansão sobre as lavouras temporárias e permanentes. Como pode ser observado (Tabela 3) e, em linha com os estudos de Abdala e Ribeiro (2011), que analisa o estado de Goiás, e Daubermann et al. (2014), em análise da evolução da cultura para o Brasil, a expansão da atividade canavieira em São Paulo apresenta forte caráter de substituição tanto de pastagens, quanto de lavouras temporárias e permanentes - produção de alimentos.

Para o estado de São Paulo as pesquisas quantitativas sobre esta temática ainda são recentes, haja vista que os efeitos mais intensos do conflito pelo uso da terra no estado estão circunscritos à última década e o debate se tornou mais intenso entre 2007 e 2009, com a chamada crise de alimentos - elevação do preço das principais commodities alimentares em um curto período de tempo.

Em pesquisa recente sobre a temática para o oeste paulista, entre os anos de 2003 e 2012, Lourenzani e Caldas (2014) mostram que o aumento da atividade canavieira naquela região se dá em maior escala pela redução da atividade pecuária bovina, mas a produção de alimentos, sobremaneira da agricultura familiar, também fora afetada. Os autores evidenciam que os produtos que mais apresentaram reduções de áreas foram aqueles característicos da pequena produção, tais como as frutas, tomate, mandioca, arroz, feijão e café. Ou seja, em regiões onde predomina a atividade rural familiar, a mudança da estrutura agrícola pode criar riscos à segurança alimentar, afetar a capacidade de produção das comunidades locais, impactar no preço da terra e a distribuição da renda agrícola.

Tabela 2 - Taxas e fontes de crescimento do valor da produção da cana de açúcar em São Paulo- período de 1995 a 2013 (em \%)

\begin{tabular}{c|c|c|c|c}
\hline \multirow{2}{*}{ Período } & \multicolumn{4}{|c}{ Cana-de-açúcar } \\
\cline { 2 - 5 } & $\begin{array}{c}\text { Variação Total } \\
(\mathrm{em} \%)\end{array}$ & $\begin{array}{c}\text { Efeito área } \\
(\mathrm{em} \%)\end{array}$ & $\begin{array}{c}\text { Efeito rendimento } \\
(\mathrm{em} \%)\end{array}$ & $\begin{array}{c}\text { Efeito preço } \\
(\mathrm{em} \%)\end{array}$ \\
\hline $1995 / 2001$ & 60,86 & 13,64 & 0,05 & 47,16 \\
\hline $2002 / 2007$ & 17,93 & 46,20 & 8,51 & $-36,78$ \\
\hline $2008 / 2013$ & 47,44 & 13,67 & $-8,47$ & 42,24 \\
\hline
\end{tabular}

Fonte: Elaborado com dados de PAM/IBGE (2015), Ipeadata (Ipea, 2015) e IEA/SP (2015). 
Tabela 3 - Taxas e fontes de crescimento da área cultivada das atividades agrícola no estado de São Paulo - período de 1995 a 2013 (em mil hectares)

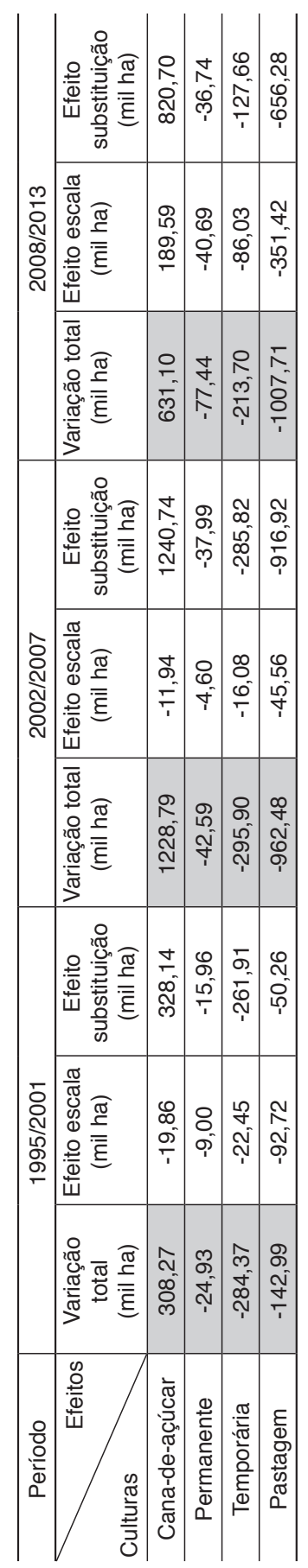

Fonte: Elaborado com dados de PAM/IBGE (2015) e IEA/SP (2015).

Nota: Em culturas temporárias exclui-se a cana de açúcar, que é analisada separadamente. Considera-se como área de pastagem a soma de capim para semente, pastagem natural e pastagem cultivada. 
Ainda de acordo com a Tabela 3, é possível asseverar que a principal fonte de explicação do crescimento da área de cana para o estado de São Paulo é o efeito substituição. Para o subperíodo de 1995 a 2001, esse efeito explicou $106 \%$ do crescimento da área, o qual mais que compensou as perdas com escala de produção. Desses 328,14 mil hectares de expansão da cana relativos à substituição, a soma entre lavoura temporária e permanente foi responsável por ceder 277,87 mil hectares e a área de pastagem 50,26 mil hectares.

Considerando o subperíodo de 2002 a 2007, observa-se, novamente, a predominância do efeito substituição como fator de expansão da cana, responsável por $100,9 \%$ da variação total da área. Nesse caso, dos 1.240,74 mil hectares de expansão da cana relativos à substituição de outras culturas, as lavouras temporárias e permanentes cederam 37,99 e 285,82 mil hectares, respectivamente, e a área de pastagem 916,92 mil hectares.

O último subperíodo, 2008 a 2013, apresenta a maior contribuição do efeito substituição para a expansão da atividade canavieira, aproximadamente $130 \%$, e dos 820,70 mil hectares relativos à expansão da cana em decorrência da redução de outras atividades, cerca de 164,40 mil hectares foram incorporados de culturas temporárias e permanentes e 656,28 mil hectares foram incorporados de áreas de pastagens. Os resultados corroboram a hipótese de Nyko et al. (2013).

Pode-se observar, com os resultados apresentados, que a expansão da cana no estado de São Paulo apresenta um conflito pelo uso da terra, pois quando analisado o seu período de maior expansão, 1995 a 2013, observa-se que a atividade afetou tanto as áreas de pastagens, sobretudo na classe pastagem cultivada, quanto afetou sobremaneira as lavouras temporárias e permanentes.

Destarte, a expansão da área foi um fator relevante para atividade canavieira em São Paulo, e os resultados apresentados chamam a atenção para o componente substituição que fora observado, o que evidencia um conflito pelo uso da terra e seus possíveis desdobramentos. Essa análise é corroborada ao observar a elevada especialização da economia agrícola e uso da terra no estado para cana, aproximadamente $66,61 \%$ do total em 2013 de acordo com IBGE (2015).

Essa análise, ao traçar um paralelo com os indicadores de produtividade, permite inferir que a produtividade não tem sido um ponto relevante para a atividade no estado. Posto isso, é presumível que as transformações na estrutura agrícola advindas do setor sucroenergético possam criar riscos à segurança alimentar. Conquanto exista uma maior geração de emprego e renda relativos à expansão do setor sucroenergético, é preciso observar como as mudanças no uso da terra afetam a capacidade de produzir de comunidades locais - agricultura familiar -, considerando sua influência sobre o preço da terra, concentração fundiária e de outros insumos produtivos e, principalmente, no preço dos alimentos. 


\section{Conclusões}

Este artigo foi realizado com o objetivo de avaliar os impactos da expansão canavieira no estado de São Paulo e seus desdobramentos sobre o possível conflito pelo uso da terra, no período de 1995 a 2013. À vista disso, o estudo identificou importantes pontos nesta discussão profícua. Incialmente, observou que a evolução do setor canavieiro em São Paulo baseou-se predominantemente em expansão territorial - efeito área - e incentivos de mercado - efeito preço real -, diante disso, infere-se que as contribuições da produtividade para esse segmento foram diminutas no período em análise. Ao traçar um paralelo com os indicadores de produtividade da cana, corroborou-se tal afirmativa.

Pormenorizada a análise do efeito área, por meio dos subefeitos escala e substituição, tornou-se bastante evidente que a o setor canavieiro em São Paulo tem apresentado um conflito pelo uso da terra por meio da substituição de culturas. Na literatura sobre o assunto alguns apontamentos davam conta de que essa substituição estava circunscritas às áreas de pastagens naturais, contudo os resultados apresentados neste artigo mostraram que não. A despeito de o método utilizado ser de natureza indicativa e não determinística, é indiscutível que a cana tem incorporado no seu processo de expansão áreas de pastagens cultivadas - pecuária bovina - e lavouras temporárias e permanentes - produção de alimentos.

O conjunto de informações deste artigo traz fortes elementos de que a produção de alimentos no estado de São Paulo tem sido afetada pela expansão canavieira. Conclui-se que se trata de uma estratégia menos custosa de expansão da produção; comparativamente aos incrementos pela via de melhoramentos e tecnologia, como investimentos na geração de biocombustíveis de segunda geração. Mesmo ponderada a possível contribuição do setor sucroenergético para a geração de emprego e renda, ainda assim as transformações agrícolas subjacentes do fenômeno em análise são preocupantes, porquanto além dos possíveis efeitos diretos sobre o preço dos alimentos, a reconfiguração do mundo agrícola decorrente da aludida expansão afeta também questões como posse da terra, capacidade produtiva da agricultura familiar, preço dos insumos, uma discussão, por assim dizer, fundamental em um país com características fundiárias como o Brasil.

Posto que um conflito pelo uso da terra esteja em curso no estado, exsurge a necessidade de se mensurar os possíveis resultados deste processo, sobretudo estudos para regiões em que predomina a agricultura familiar. Ademais, é necessária uma melhor compreensão desse fenômeno em sua relação com os preços dos alimentos, em que tais questionamentos são colocados como sugestões a estudos futuros. 
Notas

1 A edição original deste livro foi publicada em 1971, sendo citada a $39^{\circ}$ edição em português, a qual foi consultada.

2 Deve-se mencionar que a referência de dados da Pesquisa Agrícola Municipal (PAM) do IBGE é sempre apresentada em relação ao ano civil enquanto os dados da Unica estão em termos de ano safra. As informações são utilizadas de forma alternada neste estudo, de acordo com a necessidade, contudo, sempre destacando a ênfase que se dá a terminologia ano (usada para ano civil e dados do IBGE) e ano safra ou safra para os dados da Unica.

3 Essa taxa foi calculada considerando 1995 a 2013.

\section{Referências}

ABDALA, K. O; RIBEIRO, F. L. Análise dos impactos da competição pelo uso do solo no estado de Goiás durante o período 2000 a 2009 provenientes da expansão do complexo sucroalcooleiro. Revista Brasileira de Economia, Rio de Janeiro, v.65, n.4, p.373400, dez. 2011.

ADAMI, M.; MENDES, F de S.; AGUIAR, D.A.; SALGADO, M. P. G.; RUDORFF, B.F. T, Mudança do uso da terra devido à expansão da cana-de-açúcar em São Paulo de 2005 a 2011. In: XVI SIMPÓSIO BRASILEIRO DE SENSORIAMENTO REMOTO -SBSR, Foz do Iguaçu/PR, INPE. Anais..., Foz do Iguaçu: INPE, 2013.

ANP - AGÊNCIA NACIONAL DE PETRÓlEO, GÁS NATURAL E BIOCOMBUSTÍVEIS. Anuário Estatístico Brasileiro do Petróleo, Gás Natural e Biocombustíveis 2013. Brasília: Ministério de Minas e Energia, 2013.

ARAÚJO, A. C.; CAMPOS, R. T. Análise da evolução do valor da produção de cacau no estado da Bahia. In: XXXVI CONGRESSO DA SOCIEDADE BRASILEIRA DE ADMINISTRAÇÃO, ECONOMIA E SOCIOLOGIA RURAL, 1998, Poços de Caldas.. Anais... Sober, 1998. I CD-ROM.

BACCHI, M. R. P.; CALDARELLI, C. E. Impactos socioeconômicos da expansão do setor sucroenergético no Estado de São Paulo entre 2005 e 2009. Nova Economia, Belo Horizonte, v.25, n.1, 2015.

CALDARELLI, C. E. Análise do valor da produção e da composição do mercado brasileiro de grãos. Revista de Política Agrícola, Brasília, v.19, n.2, p.21-30, 2010.

CAMARGO, A. M. M. P.; CASER, D. V.; CAMARGO. F. P.; OliveTTI, M. P. A.; SACHS, R. C. C.; TORQUATO, S. A. Dinâmica e tendência da expansão da cana-de-açúcar sobre as demais atividades agropecuárias, Estado de São Paulo, 2001-2006. Informações Econômicas, São Paulo, v.38, n.3, p.47-66, 2008.

DAUBERMANN, E. C.; CHAGAS, L. S.; GURGEL, A. C.; SAKURAI, S. N. Expansão da área agrícola e produtividade das culturas no Brasil: testando hipóteses da legislação californiana de biocombustíveis. Revista de Economia e Sociologia Rural, Brasília, v.52, n.1, p.81-98, mar. 2014. 
DEMATTÊ, J. L. I. Precision agriculture for sugarcane management: a strategy applied for Brazilian conditions. Acta Scientiarum Agronomy., v.36, n.1, p.111-17, jan.-mar., 2014.

DURIGAN, G.; SIQUEIRA, M. F.; FRANCO, G. A. D. C. Threats to the Cerrado remnants of the state of São Paulo, Brazil. Scientia Agricola, Piracicaba, v.64, n.4, p.35563, 2007.

GALEANO, E. As veias abertas da América Latina. Trad. Galeno de Freitas. $39^{\circ}$ ed. Rio de Janeiro: Paz e Terra, 2000. 307p. (Coleção Estudos Latino-Americanos, v.12).

GILIO. L. Análise dos impactos socioeconômicos da expansão do setor sucroenergético. Piracicaba, 2015. 86p. Dissertação (Mestrado em Economia Aplicada) - Escola Superior de Agricultura "Luiz de Queiroz”, Universidade de São Paulo. Piracicaba, 2015.

HOFFMANN, R. Segurança alimentar e produção de etanol no Brasil. Segurança Alimentar e Nutricional, Campinas, v.13, n.2, p.1-5, 2006.

IBGE - INSTITUITO BRASILEIRO DE GEOGRAFIA E ESTATÍSTICA. Pesquisa Agrícola Municipal - PAM. Brasília: 2015. Disponível em: <http://www.sidra.ibge. gov.br/>. Acesso em: 20 jan. 2015.

IEA/SP - INSTITUTO DE ECONOMIA AGRÍCOLA DE SÃO PAULO. Estatísticas da produção paulista. São Paulo: 2015. Disponível em: <http://www.iea.sp.gov.br/ out/bancodedados.html>. Acesso em: 20 fev. 2015.

INPE. MAPEAMENTO DE CANA VIA IMAGENS DE SATÉLITE DE OBSERVAÇÃO DA TERRA - CANASAT. Tabelas de produção por municipio do Estado de São Paulo. Disponível em: <http://www.dsr.inpe.br/laf/canasat/tabelas.html>. Acesso em: 10 out. 2014.

IPEA - INSTITUTO DE PESQUISA ECONÔMICA APLICADA. Ipeadata. Brasília: 2015. Disponível em: <http://www.ipeadata.gov.br>. Acesso em: 15 mar. 2015.

LOURENZANI, W. L.; CALDAS, M. M. Land use change from the sugar cane expansion in the western region of São Paulo state, Brazil. Ciência Rural, Santa Maria, v.44, n.11, nov. 2014.

MAPA - MINISTÉRIO DA AGRICULTURA, PECUÁRIA E ABASTECIMENTO. Estatísticas. Brasília: 2015. Disponível em:<http://www.agricultura.gov.br>. Acesso em: 15 fev. 2015.

MITCHELL, D. A note on rising food prices. World Bank Policy Research: Washington. Working Paper Series4682. 2008.

MORAES, M. A. F. D. D. O mercado de trabalho da agroindústria canavieira: desafios e oportunidades. Economia Aplicada, Ribeirão Preto, v.11, n.4, p.605-19, 2007.

MORAES, M. A. F. D.; ZILBERMAN, D. Production of ethanol from sugarcane in Brazil. London: Springer, 2014. 221p.

NYKO, D.; VALENTE, M.; MILANEZ, A.; TANAKA, A.; RODRIGUES, A. A evolução das tecnologias agrícolas do setor sucroenergético: estagnação passageira ou crise estrutural? Bionergia. BNDES Setorial, v.37, p.399-442, 2013.

RAJAGOPAL, D.; SEXTON, S.; HOCHMAN, G.; ROLAND-HOLST, D.; ZILBERMAN, D. Model estimates food-versus-biofuel trade-off. California Agriculture, v.63, n.4, p.199-201, 2009. 
SATOLO, L. F.; BACCHI, M. R. P. Impacts of the Recent Expansion of the Sugarcane Sector on Municipal per Capita Income in São Paulo State. ISRN Economics, Cairo, v.2013, p.1-14, 2013.

SHIKIDA, P. F. A.; AZEVEDO, P. F. de; VIAN, C. E. de F. Desafios da agroindústria canavieira no Brasil pós-desregulamentação: uma análise das capacidades tecnológicas. Revista de Economia e Sociologia Rural, Piracicaba, v.49, p.599-628, 2011.

UDOP - UNIÃO DOS PRODUTORES DE BIOENERGIA. Dados de mercado. Araçatuba: 2015. Disponível em: <http://www.udop.com.br>. Acesso em: 15 fev. 2015.

UNICA - UNIÃO DA INDÚSTRIA DE CANA-DE-AÇÚCAR. Unicadata. São Paulo: 2015. Disponível em:< http://www.unicadata.com.br/>. Acesso em: 20 jan. 2015.

VEIGA FILHO, A. A.; YOSHII, R. J. Uso da terra no estado de São Paulo: mudanças na composição das atividades agrícolas e o caso da cana-de-açúcar. Informações Econômicas, São Paulo, v.22, n.2, p.45-53, 1992.

YOKOYAMA, L. P.; IGREJA, A. C. M. Principais lavouras da região Centro-Oeste: variações no período de 1975-1987. Pesquisa Agropecuária Brasileira, v.25, n.5, p.727$36,1992$.

RESUMO - Este estudo tem por objetivo avaliar a expansão canavieira no estado de São Paulo e a consequente competição pelo uso do solo em relação às demais atividades agropecuárias, entre 1995 e 2013. Para tanto, utiliza-se o modelo shift-share em duas etapas; inicialmente, com vistas à decomposição da taxa de crescimento do valor da produção de cana-de-açúcar - nos efeitos área, rendimento e preço -, e, em uma segunda etapa, tencionando avaliar a evolução da área com cana-de-açúcar - nos subefeitos escala e substituição. Os resultados sugerem que a expansão canavieira em São Paulo foi impulsionada, principalmente, pelo aumento da área cultivada e preços, com baixa contribuição do efeito rendimento. Ademais, o estudo permite concluir que a evolução da atividade representa um conflito pelo uso terra no estado, fato evidenciado pela elevada contribuição do efeito substituição na expansão da área cultivada.

PALAVRAS-CHAVE: Cana-de-açúcar, Uso da terra, Modelo shift-share.

ABSTRACT - The aim of this paper is to evaluate the expansion of sugarcane and its impacts on agricultural land use in the state of São Paulo between 1995 and 2013. A two-stage shift-share model was used, first to desegregate sugarcane production values in terms of area, productivity and price effects. Then, in a second stage, the model was used to evaluate the expansion of the planted area of sugarcane in terms of scale and substitution effects. The results showed that sugarcane has expanded in São Paulo, due especially to area and price effects, with low contribution of the productivity effect. 
This article concludes that sugarcane in São Paulo represents a land use conflict; it was corroborated by the high contribution of the substitution effect in sugarcane harvest. KEYWORDS: Sugarcane, Land use, Shift-share model.

Carlos Eduardo Caldarelli é doutor em Economia Aplicada pela Esalq/USP. Professor adjunto do Departamento de Economia da Universidade Estadual de Londrina (UEL). Professor do mestrado em Economia Regional da UEL. @ - carlos.caldarelli@gmail.com Marcia Regina Gabardo Da Camara é doutora em Teoria Econômica pela FEA/USP. Professora associada do Departamento de Economia da Universidade Estadual de Londrina (UEL). Professora do mestrado em Economia Regional da UEL.

@ - mgabardo@sercomtel.com.br

Recebido em 25.9.2015 e aceito em 15.03.2016.

I, II Departamento de Economia, Universidade Estadual de Londrina, Londrina/Paraná, Brasil. 